\title{
Research on the Change of Physical Education Teaching Based on Mixed Reality Technology in the Context of Big Data
}

\author{
Hongyu Ma \\ Wuhan Technology and Business University \\ Wuhan, China
}

\author{
Jing $\mathrm{Li}^{*}$ \\ Wuhan Technology and Business University \\ Wuhan, China \\ *Corresponding Author
}

\begin{abstract}
With the rapid development of the teaching forms, such as mousse, multimedia and micro class, the teaching of intellectual education has been greatly impacted in the teaching methods and teaching theory. Although the teaching of physical education and intellectual education are juxtaposition of teaching, they are different types of teaching and have their own laws and characteristics. At present, with the continuous progress and development of virtual technology, mixed reality (MR) technology enables users to interact with real world and virtual objects in real time. This paper studies the reform of mixed reality technology and physical education by using the methods of literature, field investigation and logical analysis. Mixed reality (MR) features the combination of reality and virtual world, the precise alignment of virtual objects with the real world, and the real-time interaction of users with the real world and virtual objects.
\end{abstract}

Keywords-mixed reality technology; multi-media; teaching reform

\section{INTRODUCTION}

With the continuous development and progress of human society, the constant renewal of information technology and the rapid development of computer, network and multimedia technology, the modern society has become more and more information, and brought great changes to our lives. At the same time, it has a profound impact on all aspects of education, and people's access to information and education channels are more open and rich. The traditional teaching model, which is dominated by teachers, oriented by classroom teaching and based on theoretical education, is gradually replaced by a more open modern teaching model. With the rapid development of the teaching form such as smut, multimedia, microcourse and so on, the teaching of intellectual education is greatly impacted in the teaching mode and theory. Although physical education teaching and intellectual education teaching are parallel teaching, they are different types of teaching, with their own rules and characteristics. Because of the particularity of teaching content and mode, physical education is limited by the influence of modern information technology. At present, with the development of virtual technology, the hybrid reality (MR) technology combines the real world with the virtual world, and the virtual object is closely aligned with the real world. These characteristics of mixed reality bring an opportunity for the transformation of physical education and also create a new era for the future of physical education. We should keep up with the pace of the times, fully draw lessons from the experience and achievements already made, and apply the mixed realistic technology to the teaching of physical education in our country, create a favorable teaching environment for teachers by drawing on the highquality teaching resources at home and abroad, further improve the level of physical education in our country, and conduct modern physical education with Chinese characteristics and world level.

\section{RESEARCH OBJECTS AND METHODS}

\section{A. Document Method}

This article through Wuhan university library, Wuhan vocational and technical college library, sports review database and other relevant books, periodicals focus on "sports teaching reform", "mixed reality technology" and other relevant literature, and looked through the school physical education, sports principles, education, educational psychology, action learning and control related books, to obtain more systematic basic theoretical knowledge, for this research laid a solid foundation.

\section{B. Field Investigation Method}

Through exchanges with experts and professors from Wuhan University's computer Institute and wushu vocational technical college, as well as personal experience of motion capture instruments, processing, display equipment and supporting software systems at the virtual laboratory of the University of computer science, relevant information on mixed reality technologies is obtained.

\section{Logical Analysis}

Through summarizing and collating the relevant materials and data of physical education reform and mixed reality technology, through in-depth analysis and discussion, relevant conclusions and recommendations are obtained. 


\section{RESULTS AND ANALYSIS}

\section{A. Mixed Reality Technology to Promote the Reform of Physical Education}

After the reform and opening up, China's education experienced three important changes: the period of restoration and reconstruction in the early period of founding (1979-1984), the period of introduction and reference after rapid economic development (1985-1999) and the period of deepening reform under the knowledge economy (20002009). With the rapid development of modern information technology, Bi will bring about the third important change of our education. Although physical education teaching and intellectual education teaching is juxtaposed teaching, they are different types of teaching, with their own rules and characteristics. Physical education is a kind of practical and intuitive teaching, because of the particularity of teaching content and mode, it needs to be taught by words and deeds. Only through accurate demonstration and explanation, necessary and proper practice, full and effective feedback and establishing stable and clear kinesthetic sense can we gradually learn and master the sports techniques and methods of various physical activities.3With the rapid development of the teaching of computer science, multimedia, microteaching and so on, it has a profound influence on the teaching of intellectual education, but it has limited influence on the teaching of physical education based on operation skills. At present, the combination of reality and virtual reality, the precise alignment of virtual objects with the real world, the real world and virtual objects can be used in physical education teaching. Innovation physical education teaching method, change traditional physical education teaching mode; (b) Providing individualized teaching and teaching according to their qualifications; Transform the way of study and mobilize the enthusiasm of study.

1) Optimizing teachers to promote the modernization of sports teaching content: Teaching content is the foundation of physical education teaching and an important aspect of deepening the transformation of physical education teaching. At present, the teaching content is relatively old and cliché because the teaching level of physical education teachers in our country is different. The mixed reality technology can integrate the high quality teachers 'resources, promote the modernization of the teaching content of physical education, promote the development of the teaching content of physical education in the direction of diversification, diversification, efficiency and soft sports.

By integrating teachers 'resources to collect, organize and analyze data on different sports items, the mixed reality technology can promote the diversity and diversification of sports teaching content, fully mobilize the enthusiasm of students to participate, and optimize the effect of sports learning and exercise. Students who leave school and enter the society can still learn and exercise sports by mixing practical technical equipment, promoting the long-term content of teaching, avoiding the embarrassment of spending time and time on sports skills, linking the content of school sports learning to social sports, bringing it closer to people's lives, and actually putting into practice lifelong sports ideas.

2) Innovating the teaching methods of physical education and changing the traditional sports teaching mode: Modern education has changed markedly in the information age, and people's learning channels are more abundant, from the Helbat School's teaching practice model, which is dominated by teachers, oriented by classroom teaching and based on theoretical education, to the guiding teaching and discovery learning. There is no law in teaching. At present, the teaching methods of physical education and traditional intellectual education are basically the same. Although physical education teaching and intellectual education teaching is juxtaposed teaching, they are different types of teaching with their own rules and characteristics. At present, there are many kinds of teaching methods, such as mousse, multimedia, microteaching. With the rapid development of the teaching of computer science, multimedia, microteaching and other kinds of information technology, it has a profound influence on the teaching of intellectual education, but it has a limited influence on the teaching of physical education, which cannot be regarded as the main way of physical education. The hybrid reality (Mr) has the characteristics of combining the real world with the virtual world, aligning the virtual objects with the real world accurately, and the users can interact with the real world and the virtual objects in real time.

3) Provide individualized teaching and teach students in accordance with their aptitude: At present, the class system is my holiday school teaching basic organization form. Although the class system is more efficient than individual teaching, a teacher can teach dozens of students at the same time, but the class teaching emphasizes collectivization, synchronization, standardization, but is not good at taking care of students 'individual differences, individual guidance to students, not to train students' interests, special skills and the development of their personality, according to the skills of teaching can only be the educators hope. 6 Through the application of mixed reality technology in physical education teaching, the students can be provided with personalized teaching, and the teachers can really change from educators who emphasize oneness to teachers who give reasons. On the platform of mixed reality technology, students can choose different content according to their own needs and levels, make teaching more open and targeted, and make teaching and individualized teaching become a reality.

4) Change the way of learning and arouse the enthusiasm of learning: Traditional physical education teaching, teaching materials and teachers in a dominant position, teachers 'demonstration and explanation is a model of learning, students also implement simple mechanical imitation and learning, failed to mobilize students' learning enthusiasm and initiative; "teaching hard, learning pain" has become a common phenomenon in physical education 
teaching. Mixed reality technology can change the original single, passive way of learning, from accepting learning to discovering learning, avoiding too much emphasis on students to accept and master the action. The aim is to establish and form a variety of learning ways to fully mobilize and bring into play the subjectivity of students, and to promote students to study actively and individually under the guidance of teachers, so as to foster students 'innovative spirit and practical ability. 7 Truly establish the student's main body position, the physical education teacher also from the teaching leader to the sports ability guide and the overall development of the promotion.

\section{B. The Strategy of Sports Teaching in Mixed Reality}

Modern information technologies change the way in which human beings receive and disseminate knowledge. The education form such as modern class, multimedia, microcourse has changed the way of human intellectual education, mixed reality technology has opened up a new era for the future of physical education, we should speed up the research and implementation of the application of mixed reality technology in physical education, occupy the high point of physical education teaching.

1) Establishing a special platform of mixed reality sports teaching to realize network and shared learning: We should seize the opportunity to increase funding and scientific research investment in mixed real technology, and accelerate the establishment of exclusive platform for mixed real sports teaching, and occupy the high point of sports teaching. At present, we can capture the movement of limbs, torso and head through mixed reality technology, collect the motion data, analyze and process the relevant data through mixed reality technology, and add the relevant data according to the teaching goal and teaching content. The human eye can see the teacher's action demonstration and demonstration through the display device of mixed reality, the practice can superimpose itself with the standard action, and can see the virtual coach to correct his own action to get timely feedback, and each technical action and request get the relevant specific explanation and analysis, under the teacher's guidance. Choose different content according to their own needs and level to exercise and learn. At the same time, students can try different roles such as coach, referee, team member, organiser in the mixed reality, and can carry on the competition training with the virtual opponent. Then, on the basis of the individual project teaching, we use the mixed reality technology to integrate and share a lot of sports teaching content, so that more and more people can learn and exchange through the network, and finally establish the sports teaching platform to meet the students 'abundant needs of sports culture, and realize the network and sharing of sports teaching.

2) Training professional team to produce mixed realistic physical education course: We should speed up the formation of professional teams to integrate specialists, academics and sports professionals in sports, pedagogy, psychology, computer science, school sports, sports training, game development, and so on, and make a series of complete implementation plans for the application and evaluation of courses, course management, evaluation and quality evaluation. Ensure the quality of mixed physical education. Under the background of mixed reality technology, sports teaching should put people first. The goal of teaching is not only to train students to adapt to the traditional world, but also to focus on practical sports knowledge and skills. Let students love sports, recognize the value of sports, develop the habit of lifelong sports, leave school environment can be independent, informed consumers, in order to better adapt to the future; According to the characteristics of students 'physical and psychological development, the teaching content should be set up according to the corresponding content and curriculum system, and the related sports skills should be collected, collated and processed with a great deal of data, and a large mixed physical education curriculum system should be established. At the same time, sports teaching in our country can use the advantage of mixed reality, introduce highquality sports training and teaching content at home and abroad, share high-quality resources, and speed up the construction of mixed realistic sports curriculum through various channels.

3) Exploring the sustainable development mode of mixed reality physical education teaching: The construction and operation of mixed physical education needs a lot of manpower, material and financial resources. It is not conducive to the long-term development of mixed physical education to rely on the form of school and government, so we should establish a reasonable mechanism for the operation and development of mixed physical education platform, strengthen cooperation between schools and enterprises, market development and so on, and promote the sustainable development of mixed physical education through various channels.

\section{CONCLUSION}

\section{A. Conclusions}

- Although physical education teaching and intellectual education teaching are parallel teaching, they are different types of teaching with their own laws and characteristics. Physical education teaching is a kind of skill teaching, because of the particularity of teaching content and mode, it can not be regarded as the main way of physical education teaching because of the limited influence and impact of various teaching methods, such as smut, multimedia and microteaching.

- Virtual Reality (VR) is a pure virtual digital screen with Super simulation effect; Enhanced reality(AR) is a virtual digital picture superimposed on the real world, which can produce sensory experience beyond reality, but ignores the real world itself. Mixed 
Reality (MR) has the characteristics of combining reality with virtual world, accurate alignment of virtual object with real world, and real-time natural interaction with real world and virtual object.

- With the continuous development of virtual reality technology, mixed reality technology brings an opportunity for the transformation of physical education and teaching, and can promote the modernization of physical education and teaching content by optimizing teachers; Innovation physical education teaching method, change traditional physical education teaching mode; (b) Providing individualized teaching and teaching according to their qualifications; Transform the way of learning and mobilize the enthusiasm of learning to promote the reform of physical education teaching.

- Network and shared learning through the establishment of an exclusive platform for mixed physical education; Cultivate professional team to produce mixed realistic sports curriculum; Exploring the sustainable development of mixed physical education. The application of mixed reality technology in physical education teaching.

\section{B. Suggestions}

Mixed reality technology has opened a new era for the future of physical education. We should keep abreast of the times, increase our human, material and financial resources, and invest in mixed physical education, speed up the development of professional team building and mixed physical education courses, and draw on the experience and achievements already made, as well as high-quality teaching resources at home and abroad, to develop modern physical education with Chinese characteristics and world standards.

\section{ACKNOWLEDGEMENT}

Fund program: Provincial Teaching Research Project of Hubei provincial higher education institutions in 2016, Fund No.: 2016445.

Humanities and Social Sciences research project of Hubei Provincial Education Department. Fund No.:17G090

\section{REFERENCES}

[1] Shao xishan, Liu yao. Analysis of the Characteristics of Physical Education Teaching Different from that of Intellectual Education $[\mathrm{J}]$ I'm sorry. Sports master, 2002.2:47-48.

[2] Zhao Li. Continuing and Development: 30 Years of Change in Physical Education in Basic Education(1979-2009) [D] -I'm sorry. Nanjing Normal University, 2012.

[3] Feng Zhongliang, Wu Xinchun, etc.. Educational Psychology[ [M] I'm sorry. Beijing: People's Education Press, 2003:421-429.

[4] Tang Zhuohui, Zhu Peiyi. Virtual reality, augmented reality and hybrid reality and their application in the rail transport industry [J] I'm sorry. Railway Communication Signal Engineering, 2016, 05:7982.

[5] Yang Wenxuan, Chen Qi. Sports Principles [M] Beijing: Higher Education Press, 2012:107-112.
[6] Wang Daojun, Wang Hanlan. Education [M] -I'm sorry. Beijing: People's Education Press, 2008:265. 